\section{A revolta de Lab'ayu. As cartas de Tell el-Amarna e o contexto político de Canaã antes de Israel*}

José Ademar Kaefer ${ }^{a}$

Universidade Metodista de São Paulo (UMESP) Brasil http://orcid.org/0000-0003-1607-2810

RECEBIDO: 29-05-18. APROVADO: 20-09-18

Resumo: O objetivo deste artigo é apresentar a revolta que aconteceu em Canaá, sob a liderança de Lab'ayu, governante de Siquém, um pouco antes do surgimento de Israel, e que teve a adesão de várias cidades-Estado da regiáo. $\mathrm{O}$ estudo será feito através da análise das cartas encontradas em Tell el-Amarna e que foram enviadas ao faraó por Lab'ayu, governante de Siquém (EA 252-254), por Tagi, governante de Ginti-Kirmil (EA 264-266), e por Mut-Ba'lu, governante de Pella (EA 255-256). Constata-se na referidas cartas que o território conquistado pela revolta de Lab'ayu é similar ao que o rei Saul, primeiro rei de Israel, ocupou alguns séculos depois.

Palavras-chave: História de Israel; Lab'ayu; Siquém; Tagi; Mut-Ba'lu; Pella; Tell el-Amarna.
The Lab'ayu Revolt. The Letters of Tell el-Amarna and the Political Context of Canaan before Israel

Aвstract: The purpose of this article is to present the revolt that took place in Canaan under the leadership of Lab'ayu, ruler of Shechem, shortly before the emergence of Israel, which had the adhesion of several city-states of that region. The study will be done by analyzing the letters found at Tell el-Amarna and sent to Pharaoh by Lab'ayu (EA 252-254) by Tagi, ruler of Ginti-Kirmil (EA 264-266), and by Mut-Ba'lu, ruler of Pella (EA 255-256). It is noted in these letters that the territory conquered by the Lab'ayu revolt is similar to what King Saul, the first monarch of Israel, occupied a few centuries later.

KeY words: History of Israel; Lab'ayu; Shechem; Tagi; Mut-Ba'lu; Pella; Tell elAmarna.Hermeneutics.

\section{Cómo CITAR:}

Kaefer, José Ademar. "A revolta de Lab'ayu. As cartas de Tell el-Amarna e o contexto político de Canaã antes de Israel". Theologica Xaveriana 188 (2019): 1-17. https://doi.org/10.11144/javeriana. $\underline{\text { tx69-188.rlctec }}$

\title{
ReCONHECIMENTO
}

Este artigo é fruto do projeto de pesquisa coordenado pelo autor, que visa o estudo do contexto cananeu prévio a Israel. É também parte resultante do pós-doutorado realizado no Departamento de Arqueologia da Universidade de Tel Aviv, sob a orientação do professor Israel Finkelstein.

*Artigo de investigação

${ }^{a}$ Autor de correspondencia. Correio eletrônico: jademarkaefer@gmail.com 


\section{Introdução}

As cartas encontradas em de Tell el-Amarna no final do século XIX e início do século XX de nossa era se tornaram a maior fonte de informação sobre as relaçóes políticas entre o Egito e os reinos da Mesopotâmia do período do Bronze Tardio (1550-1200). Ainda que o teor principal das cartas seja os assuntos políticos, as entrelinhas trazem também informaçôes sobre a cultura, a diplomacia, a escrita, o comércio, a religião, as guerras, a administração, o domínio, a submissão, o tráfico humano, a comida, o vestuário, os casamentos etc.

Boa parte das cartas foi enviada pelos reis dos grandes reinos de então, como Babilônia, Assíria e Mitani. Outra parte pelos governantes ${ }^{1}$ vassalos das grandes cidadesEstado ou reinos menores situadas principalmente na costa do mar Mediterrâneo, como Gaza, Asquelon, Asdod, Tiro, Sidônia, Biblos, Ugarit etc. Uma terceira parte foi enviada pelas cidades-Estado centro e sul de Canaã.

E são estas últimas que mais nos interessam, pois elas mostram, entre outros assuntos, que durante os reinados de Amenhotep III (1390-1352) e Amenhotep IV, Akenaton (1352-1336) ${ }^{2}$, provavelmente com predominância desse último reinado, aconteceu em Canaã uma grande rebeliáo contra o Egito. A revolta foi liderada por Lab'ayu, governante de Siquém, que iniciou a insurreição nas montanhas centrais de Canaã e a estendeu, para o sul, conquistando a importante cidade-Estado de Guezer e ganhando a simpatia de seu governante, Milkilu (El-Amarna, EA, 250; 267-271; 289).

Também a estendeu para o oeste, em direção à cidade-Estado de Ginti-Kirmil, onde governava Tagi. E, ainda, para o leste, em direção à Pella, no além Jordão, onde governava seu filho Mut-Ba'lu. Quando ameaçava conquistar o Vale de Jezreel, o celeiro egípcio, e controlar a mais importante rota comercial da regiáo, a Via Maris, o Egito interveio e Lab'ayu foi preso e morto em Meguido, durante um cerco àquela que era a base militar egípcia por excelência (EA 244 e 245).

Conhece-se pouco de como se deu o processo da revolta siquemita, assim como se sabe pouco sobre Lab'ayu, seu líder. Por isso, o objetivo aqui é abordar as cartas encontradas em Tell el-Amarna enviadas pelo próprio Lab’ayu ao rei do Egito. Também vamos analisar as cartas enviadas por seus dois aliados mais próximos: Tagi, governante de Ginti-Kirmil, e Mut-Ba'lu, filho de Lab’ayu e governante de Pella.

\footnotetext{
${ }^{1}$ Evidentemente que não era o governante que escrevia a carta, mas, um escriba, que, em muitos casos, era buscado em outra cidade-Estado. A escrita era cuneiforme, com grande predominância do acádico médio-babilônico.

${ }^{2}$ Kaefer, "As cartas de Tell El-Amarna e o contexto egípcio nos reinados de Amenhotep III e Amenhotep IV (Akenaton)", 121-140.
} 


\section{Siquém}

Siquém (Tell Balatah), está localizada no planalto central de Canãa, mais tarde conhecida como montanha de Efraim, cerca de dois quilômetros da cidade de Nablus. A localização é estratégica, entre os montes Garizim e $\mathrm{Ebal}^{3}$, para controlar, de um lado, a via que vem do Vale do Jordáo, no leste, pelo Wadi Far'a, até a costa mediterrânea, no oeste. E, por outro, o caminho que vem do norte, até Jerusalém e Hebron, no sul (Os 6,9). Estratégico também para controlar o fértil Vale de Sahl al-Mah, defronte do Monte Garizim4.

No período das cartas de Amarna, Siquém era uma das cidades-Estado mais importantes de toda Canaã. Provavelmente controlava boa parte das montanhas centrais. De acordo com Finkelstein e Na'aman ${ }^{5}$, o território de Siquém estava demarcado mais ou menos da seguinte forma. Ao sul, a divisa ia até o território de Jerusalém, mais ou menos perto de Betel. Ali haviam áreas escassamente habitadas "uma terra de ninguém". Ao sudoeste, o limite ia até o território da poderosa cidade-Estado de Guezer. A oeste, até Ginti-Kirmil. A noroeste, até Ta’anach ou um pouco além, até a poderosa Meguido. E a leste limitava com Rehov. As montanhas de Siquém, contudo, não eram muito habitadas ${ }^{6}$, o que propiciava ações de bandos armados, pois o exército pouco chegava até lá.

Em Tell el-Amarna foram encontradas três cartas enviadas por Lab'ayu: EA 252, 253 e 254. Vejamos7.

EA 252: "Quando as formigas são feridas elas atacam de volta"

O tablete contêm 31 linhas, apresentaremos somente as linhas de maior relevância. Como todas as cartas dos vassalos contêm uma longa fórmula de apresentação, submissão e prostração, que é bastante similar em todas elas ${ }^{8}$, consideramos não ser necessário que todas sejam transcritas na íntegra.

${ }^{3}$ Talvez provenha dali o significado de seu nome "ombro/s" ou "pescoço" entre as montanhas.

${ }^{4}$ Bogaert y otros, Diccionario enciclopédico de la Biblia, 1993.

${ }^{5}$ Goren, Finkelstein, e Na'aman, Inscribed in Clay: Provenance Study of the Amarna Letters and other Ancient Near Eastern Texts, 262.

${ }^{6}$ Finkelstein e Na'aman, "Shechem of the Amarna Period and the Rise of the Northern Kingdom of Israel", 172.

${ }^{7}$ Seguimos as traduçóes ao inglês de William L. Moran, The Amarna Letters; Anson Rainey. The ElAmarna Correspondence. A New Edition of the Cuneiform Letters from the Site of El-Amarna Based on Collations of all Extant Tablets.

${ }^{8}$ Mynarová, "A Comment on the Opening Passages of the Amarna Letters. Its Structure and Its Address", 397-406. 
(1-4): Diga ao rei, meu senhor, a mensagem de Lab’ayu, seu servo. Aos pés do meu senhor eu caio.

(5-9): Como você escreveu para mim: "Mantenha vigilância nos homens que tomaram a cidade", como eu poderia vigiar esses homens? Pela violência a cidade foi tomada.

(10-15): Quando eu jurei meu voto de paz, quando eu jurei, o oficial sênior jurou comigo - a cidade, com meu Deus, foi tomada. Ele me humilhou (eu fui humilhado) diante do rei, meu senhor.

(16-22): Além do mais, quando as formigas são feridas, elas não atacam de volta e mordem a mão do homem que as feriu? Como estou sendo pressionado nesse tempo. E duas das minhas cidades foram tomadas.

Lab'ayu não identifica a sua cidade-capital e de onde escreve. Siquém só aparece como sendo território de Lab'ayu na carta de 'Abdi-Heba (EA 289,18-24), onde o governador de Jerusalém acusa Lab'ayu de ter concedido a terra de Siquém aos 'apirus. De maneira que, parece não haver dúvidas de que Siquém seja a capital de Lab'ayu'. A origem petrográfica ${ }^{10}$ do tablete das montanhas centrais de Canaã, também corrobora com essa certeza ${ }^{11}$.

O conteúdo náo é muito claro. A carta aparenta ser uma resposta à outra, na qual Lab'ayu parece ter sido repreendido pelo faraó por sua conduta em permitir que a cidade ou cidades fossem tomadas. Como mencionado acima, na EA 289,18-24 'Abdi-Heba, governante de Jerusalém, acusa Lab'ayu de dar territórios aos 'apirus, que parece ser a causa da admoestaçáo aqui. A mesma acusaçáo 'Abdi-Heba faz na EA 287,6-13.29-31, com a diferença de que ali ele acusa os filhos de Lab'ayu. Lab'ayu não aceita a repreensão e acusa o comissário do faraó de tê-lo difamado diante do rei.

Apesar de manifestar certa submissão (1-4.23-31), bem menor que as longas fórmulas que as cartas de outros vassalos costumam apresentar, a postura de Lab'ayu é bastante perpicaz. Sua mensagem ao faraó é muito clara: "Quando as formigas são feridas, elas não atacam de volta e mordem a mão do homem que as feriu?” Parece ser ameaça clara. Um sinal evidente de que "a machadinha de guerra foi desenterrada". Estaríamos aqui, então, no início da revolta siquemita, quando ainda havia diálogo entre o faraó e o líder rebelde? Difícil saber ao certo. Vejamos o que diz a carta seguinte.

\footnotetext{
${ }^{9}$ Campbell, "Shechem in the Amarna Archive", 195.

${ }^{10}$ Goren, Finkelstein e Na'aman, Inscribed in Clay: Provenance Study of the Amarna Letters and other Ancient Near Eastern Texts, 264-265.

11 "A evidência textual, juntamente com os dados petrográficos, confirmam que Siquém é a única localização possível para esse governante". ("The textual evidence together with the petrographic data shows Shechem to be the only possible location for this ruler"). (Goren, Finkelstein e Na'aman, Inscribed in Clay: Provenance Study of the Amarna Letters and other Ancient Near Eastern Texts, 265).
} 


\section{EA 253: Lab’ayu é acusado de rebeldia e delinquência}

(7-17): [eu tenho es]cutado as palavras [que] o rei, meu senhor, escreveu para mim [n]o tablete. [Veja] eu sou o servo do rei [como] meu [pa]i e [o pa]i [do] meu pai era um servo do rei desde antigamente e eu não me rebelei e eu não tenho sido delinquente.

(18-31): Veja meu crime e veja minha delinquência de que eu tenha entrando na cidade de Gezer e falado isso: "O rei nos está punindo!" Assim, não há outra intenção do que servir o rei. E tudo o que o rei disser eu farei.

(32-35): Talvez o rei me mantenha no encargo do meu comissário [a fim de] proteger a ci[dade do rei].

Novamente temos uma carta-resposta a uma anterior, na qual o faraó parece acusar Lab'ayu de rebeldia e delinquência. É possível até que ele tenha sido destituído de seu posto de governante (32-35). Lab'ayu se defende recorrendo à boa conduta dos seus antepassados, pai e avô, que, segundo a carta, sempre foram fieis ao faraó ${ }^{12}$. $\mathrm{E}$ assim parece ter sido, do contrário a dinastia não se teria mantido no poder.

O problema da relação estremecida entre o Egito e seu vassalo parece ser Guezer, cidade-Estado governada por Milkilu, e que, pelas informaçóes aqui, foi invadida por Lab'ayu. Sabemos por outras cartas (EA 250; 267-271; 289), que Milkilu, com Guezer, tornou-se o grande aliado de Lab'ayu. Como se deu essa aliança entre os dois governantes não está claro. Se Lab'ayu invadiu Guezer e forçou Milkilu a se aliar a ele ou se foi uma adesão espontânea. $\mathrm{O}$ fato é que invadir a grande Guezer e conquistá-la é uma demonstração, ao mesmo tempo, de audácia e de força da insurreição siquemita. E, esse parece ser o temor egípcio, a expansão da revolta e a adesão de importantes cidades-Estado. Na terceira carta, as acusaçóes contra Lab'ayu continuam.

\section{EA 254: Lab'ayu toma as terras do rei}

(6-10): Eu tenho obedecido às palavras que o rei enviou para mim. Quem sou eu para que o rei perca a sua terra por causa de mim?

(10-15): Veja, eu sou um servo leal do rei e não sou um rebelde e nem um criminoso. Eu não retive o meu tributo e não retive nada do que o meu comissário requisitou.

(16-29): Eu fui injuriado e difamado e o rei, meu senhor, não investigou se eu era culpado. Ademais, o meu ato rebelde foi simplesmente ter entrado em Gezer (Garzu) e de ter dito: "tudo o que era meu o rei tomou, mas onde estão as posses de Milkilu? Eu conheço os atos de Milkilu contra mim."

\footnotetext{
${ }^{12}$ Na'aman, "Biryawaza of Damascus and the date of Kamid El-Loz 'Apiru Leters", 181.
} 
(30-37): Além disso, o rei escreveu sobre meu filho. Eu não sabia que o meu filho estava em conluio com os 'apirus. Veja bem, eu não o entreguei nas mãos de Adaya?

(38-46): E tem mais: se o rei tivesse escrito para a minha esposa, como eu poderia retê-la. E se o rei tivesse me escrito: "enfie uma adaga de bronze no seu coração e morra", como eu não cumpriria a ordem do rei?

Mais uma carta-resposta à outra, na qual Lab'ayu novamente é acusado por parte do rei do Egito. É uma carta muito similar à anterior. A primeira acusação é de que o faraó esteja perdendo terras por causa de Lab’ayu (6-10). Ou seja, Lab’ayu estaria tomando as terras do rei. Isso parece fato, pois essa acusação já foi vista acima e também é feita por governantes de outras cidades-Estado que administravam as terras do rei do Egito (EA 244; 287; 289). A segunda acusação é de que Lab'ayu esteja retendo o tributo.

Isso é muito grave, é a gota d'água que faltava para comprovar as intençôes de lab'ayu. Reter o tributo é sinônimo de rebeldia por excelência. Por isso ele é acusado de rebelde e criminoso. $\mathrm{O}$ motivo da retenção do tributo é provavelmente a guerra. Lab'ayu necessita de mais alimentos para manter seu exército rebelde.

A briga de Lab’ayu é com Adaya, o comissário do rei, que faz a vez do faraó em Canaã. Parece que foi ele quem denunciou Lab'ayu, "fui injuriado e difamado" (16-29), que se queixa pelo fato do faraó dar ouvidos ao comissário, sem antes fazer uma investigação. Outra acusação é por Lab’ayu ter “entrado”, invadido, Guezer, ato que ele reconhece e do qual já fora acusado na carta anterior (253,18-31). Sobre o que Lab'ayu disse na carta ao entrar/conquistar Guezer (16-29) não está claro. Se ele disse que o faraó tomou suas terras, ou se é Milkilu, governante de Guezer, quem diz que Lab'ayu tomou suas terras. Uma ou outra, o problema está relacionado à toma de terras.

A carta parece demonstrar certa animosidade entre Lab'ayu e Milkilu, governante de Guezer, que em outras cartas aparece como o grande aliado de Lab'ayu. Se assim, estaríamos aqui no início da aliança entre Siquém e Guezer.

Chama a atenção o estilo diplomático da carta $^{13}$. Está evidente que as intençôes de Lab'ayu não são nada interessantes ao império egípcio. Contudo, Lab’ayu se comporta como se ele estivesse sendo a vítima e se coloca numa postura de total submissáo, inclusive de entregar a esposa ou de tirar a própria vida, se assim o rei o desejasse (3846). Ou seja, Lab'ayu parece querer ganhar tempo, evitar uma ação militar por parte do Egito e, no possível, manter as relaçóes com o imperador. Vê-se que a diplomacia já era uma arte bem desenvolvida no mundo antigo.

${ }^{13}$ Mynarová, Language of Amarna: Language of Diplomacy. Perspectives on the Amarna Letters, 2007. 
Um dos primeiros aliados da rebelião liderada por Lab’ayu foi Tagi, sogro de Milkilu e governante de Ginti-Kirmil. Vejamos!

\section{Ginti-kirmil, a cidade-estado de Tagi}

Ginti-Kirmil é uma cidade desconhecida. Ela desperta interesse por ser a suposta cidade-capital governada por Tagi, sogro de Milkilu e aliado de Lab'ayu. Em suas cartas, Tagi nunca identifica sua cidade, a referência é a EA 289,18-20, onde 'AbdiHeba, governante de Jerusalém, afirma que a cidade governada por Tagi é Ginti-Kirmil.

Para Rainey ${ }^{14}$, Ginti-Kirmil fica em algum lugar perto do Monte Carmelo e talvez nem seja a capital de Tagi, mas uma cidade que pertença a ele. Para Goren, Finkelstein e Na'aman ${ }^{15}$, a análise petrográfica das cartas, assim como o estudo arqueológico dos sítios, leva a crer que o território controlado por Tagi era mais amplo, cobrindo todo o Sharon e boa parte ou totalmente o cume do Carmelo. No sul, Ginti-Kirmil chegava até a fronteira com Java, no norte até o Tel Yokneam, no oeste fazia divisa com o mar e no leste com Meguido.

Foram encontradas três cartas enviadas por Tagi ao Egito: EA 264; 265; 266. Todas são bastante breves e de pouco conteúdo. Mesmo assim, é importante analisá-las pela importância que Tagi tem no processo revolucionário de Canaã e pelas constantes referências que as cartas de outros governantes fazem a ele.

Iremos transcrever ou comentar somente as linhas mais relevantes de cada carta. A ordem numérica invertida é em função do possível desenrolar dos acontecimentos.

\section{EA 266: O escabelo dos pés}

(8-25): Eu olhei nesta direçấo e eu o[lhei na] quela direção, mas não tinha [lu] z. Então eu [o]lhei [na] direção do rei, [meu senhor, e l]á tinha luz. Assim, [eu tenho] posto minha [fac]e para se[rv]ir [o re]i, meu senhor. Um tijolo pode se mover [de]baixo de outro [tijolo], mas eu não vou me mover de[bai] xo dos pés do [re]i, meu senhor.

(26-33): [E] agora eu [en]viei chicotes de [couro para um] corpo de ca[valos e um a] rco e [uma al]java, uma lança e cobertores para ca[valos], pa[ra] o rei, [meu] se[nhor].

\footnotetext{
${ }^{14}$ Cochavi-Raney (ed.), The El-Amarna Correspondence. A New Edition of the Cuneiform Letters from de Site of El-Amarna Based on Collations of all Extant Tablets 2, 1577.

${ }^{15}$ Goren, Finkelstein e Na'aman, Inscribed in Clay: Provenance Study of the Amarna Letters and other Ancient Near Eastern Texts, 256-258.
} 
Além da longa apresentação/humilhação (1-8), comum a todas as cartas dos vassalos, esta carta de Tagi contém um adendo único (8-25). A adulação era um artifício dos governantes, mas Tagi se sobressai. Das 33 linhas, 25 são de bajulação. Isso parece querer ocultar algo maior. De fato, Tagi é conhecido pelas cartas de seus colegas, como um dos principais sujeitos da revolta cananeia.

Não deixa de impressionar a linguagem utilizada, por um lado, para expressar o culto ao faraó, o deus sol, único ponto de onde emana luz, e por outro, a total submissão do servo vassalo, como um escabelo para os pés do faraó (8-25). Aliás, era assim que o faraó gostava de tratar os povos dominados. As sandálias de Tutankamon, encontradas em sua tumba, retratam bem esta ideologia. Na planta de cada sandália se encontram desenhados dois prisioneiros amarrados, um cananeu e um núbio ${ }^{16}$. Uma forma de, simbolicamente, pisar todo dia sobre os subalternos.

A lista de bens (tributo) enviada por Tagi ao faraó (26-33) são utensílios relacionados à lida com cavalos, talvez se trate até de alguns cavalos, "um corpo de cavalos". É a única carta das cidades-Estado de Canaã que faz menção ao envio de tais bens. Seria Ginti-Kirmil uma base de criação de cavalos para o exército egípcio? É possível. Se assim, temos aqui mais uma razão da importância de Ginti-Kirmil para Lab’ayu, garantir cavalos para a insurreição. Em todo caso, uma vez que o envio de tributos continua acontecendo, parece ser que nos encontramos num período onde a relação entre o faraó e seu vassalo ainda estavam relativamente estáveis.

A segunda carta de Tagi também é bastante breve, de apenas quinze linhas. Ela será o próximo objeto de análise.

\section{EA 265: Presentes para Tagi}

(4-15): Meu homem que eu enviei junto com os homens para contemplar a face do rei, meu senhor. [E] o rei, meu senhor, [en] viou uma remessa para mim sob o encargo de Tahmaya e Tahmaya (me) deu uma xícara de ouro, do[ze] pares de roupa de linho, para a informação do [rei], meu senhor.

Esta é uma carta-resposta, uma espécie de recibo, para atestar que a mercadoria enviada pelo rei, sob o encargo do emissário Tahmaya, chegou ao seu destino. É possível que o envio dos presentes do faraó tenha acontecido após o envio dos tributos mencionado na carta acima (EA 266), junto com os quais também foi o mensageiro de Tagi. Teríamos, então, a seguinte sequência: Tagi envia os tributos, utensílios para a lida com cavalos (EA 266), o faraó retribui enviando presentes pessoais a Tagi, que responde confirmando a chegada da remessa.

\footnotetext{
${ }^{16}$ Hendel, "The Exodus as Cultural Memory: Egyptian Bondage and the Song of the Sea", 65.
} 
O envio de presentes pelo faraó aos seus vassalos é muito comum nas cartas, era uma forma de domesticar os governantes das cidades-Estado. A xícara de ouro era provavelmente um presente pessoal para Tagi, enquanto que os doze pares de linho seriam para a família ou achegados da corte. O linho era um artigo de luxo, usado somente por as pessoas da nobreza. Na EA 369,2-14, o faraó envia roupas de linho, entre outros bens, a Milkilu, governante de Guezer, para a compra de mulheres copeiras. No Egito se fabricava muito linho, cuja planta era cultivada no Delta do Nilo. Além de vestuário, o linho era bastante utilizado no processo da mumificação.

Enfim, também nesta carta, as relaçôes entre Tagi e o faraó parecem continuar estáveis. A mesma situação parece indicar a terceira carta, a qual será analisada na sequência.

\section{EA 264: "Nossa cabeça está em vossas mãos"}

(5-13): Veja, sou um servo do rei e eu procurei reunir uma caravana sob a responsabilidade do meu homem, mas ele por muito pouco escapou de ser morto. Eu estou incapaz de enviar minha caravana ao rei, meu senhor. Assim, pergunte aos seus comissários se meu encarregado por muito pouco não foi morto.

(14-19): Além disso, veja, quanto a nós, meus olhos estão em vossa direçấo: Se devemos, subiremos para o céu. Se devemos, desceremos para o submundo. Eis que nossa cabeça está em vossas mãos.

Mais uma carta breve, que basicamente se resume em dizer que Tagi é um servo fiel e que é impossível enviar a caravana (de tributos?) ao rei. Na tentativa de fazê-lo, seu encarregado por muito pouco não teria sido morto. Não se sabe o motivo, se a caravana teria sido interceptada por bandos armados ou se Tagi está tentando iludir o faraó. Aliás, a carta apresenta um exagero de adulaçáo, muito próprio do governante. Além da fórmula introdutória de submissão/humilhação (1-4), Tagi amplia a reverência, que poderia ser intitulada de "meus olhos estáo presos aos seus" (14-19). Tagi é um sujeito no mínimo suspeito. A lisonja em demasia leva a suspeitar que Tagi esteja suspendendo o envio de tributos, e que por isso tenha sido chamado a se explicar ao faraó. Esta carta seria, então, uma tentativa de Tagi se justificar pelo não envio dos tributos.

As três cartas aparentemente retratam um ambiente pacífico. Não há menção direta a atos de rebeldia ou a conflitos com grupos armados, como os 'apirus, tão comum nas cartas de outros governantes. Tampouco há pedidos de envio de tropas regulares, assunto constante em outras cartas. Mas, a aparente tranquilidade pode estar carregada de suspeitas. Também não há evidências claras do período em que as cartas 
foram escritas. Possivelmente de Amenhotep III (1390-1352), quando as relaçóes entre o faraó e seu vassalo ainda eram estáveis.

\section{cilindro de Beth-Shean}

Em 1993 foi encontrado em Bet-Shean um pequeno cilindro de argila contendo a seguinte mensagem de Tagi para Lab'ayu: "Para Lab'ayu, meu senhor, diga: a palavra de Tagi, para o rei, meu senhor, eu tenho cumprido sua mensagem para mim"17.

Apesar do debate sobre a origem do cilindro e a correta traduçáo da mensagem, chama à atenção a maneira como Tagi se dirige a Lab’ayu, que é a mesma fórmula com que os vassalos se dirigem ao faraó ${ }^{18}$. Ou seja, Tagi tem outro senhor, Lab'ayu, o rei de Siquém e líder da revolta cananeia. Isto leva a suspeitar que a linguagem usada nas cartas de Tagi para o faraó, não tinham outro motivo senão o de ocultar as verdadeiras açôes de Tagi.

\section{Pella}

Pella, atualmente conhecida pelo nome árabe de Tabaqat Fahl, era uma cidade estrategicamente importante no mundo antigo. A localização, um pouco além do rio Jordão, junto a um entroncamento que unia as duas importantes rotas da região, o caminho dos reis, que vinha do sul da Jordânia, e o caminho do mar ou Via Maris, que vinha do Egito, permitia à Pella um grande desenvolvimento econômico e um papel importante no controle das caravanas comerciais. Razão, que mais tarde, fez Pella fazer parte da famosa liga de cidades greco-romanas conhecida por Decápolis.

Distinto do sul da Jordânia, que é muito árido, com grandes áreas desérticas, o norte tem um clima mais ameno e terras mais férteis, em especial o norte do Vale do Jordão. Pella ainda recebe os ventos úmidos do Vale de Jezreel, que trazem as chuvas do mar Mediterrâneo. Por esta razão, Pella apresenta sinais de ocupação muito antigos. Ela já aparece citada nos texto de execração egípcio do século XIX a. C., como Pihzilim ou Pihulum.

Do tempo que compreendem as cartas de Amarna foram escavadas em Pella grandes construçôes, como templos e muralhas ${ }^{19}$, sinal de que era uma cidade importante nesse período. Pella também é citada na famosa estela do faraó Seti I (1304-1290), que foi encontrada em Betsã. Nesta estela, Pella é mencionada junto com Hammat,

\footnotetext{
${ }^{17}$ Horowitz, "An Inscribed Clay Cylinder from Amarna Age Beth Shean”, 208-217.

${ }^{18}$ Na'aman, "The Contribution of the Amarna Letters to the Debate on Jerusalem's Political Position in the Tenth Century B. C. E.", 17-27.
}

${ }^{19}$ Kaefer, Arqueologia das terras da Biblia, 52-53. 
outra cidade do Vale do Jordáo, como uma das cidades que participaram da revolta contra o Egito. De forma que, Pella parece ter um histórico de revoltas ${ }^{20}$.

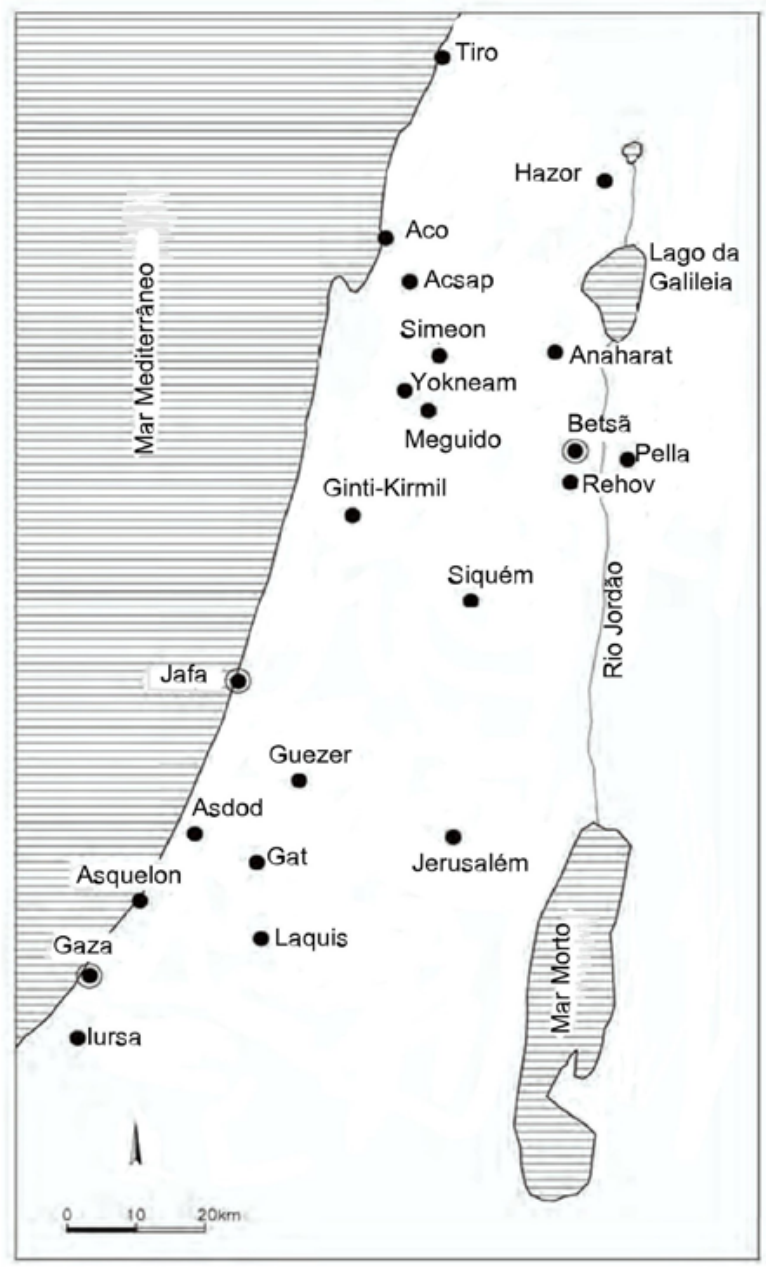

Figura 1. As principais cidades-Estado de Canaã centro e sul no período de Amarna (organizado a partir da Figura 12.1 de Goren, Finkelstein e Na'aman, Inscribed in Clay: Provenance Study of the Amarna Letters and other Ancient Near Eastern Texts, 217).

${ }^{20}$ Para o mundo moderno, Pella se tornou um sítio famoso por causa do interesse cristão. Acredita-se que durante a destruição de Jerusalém pelo exército romano em $70 \mathrm{~d}$. C., os cristãos tenham se refugiado em Pella (Mc 13,14; Lc 21,20-21; 19,4-44; Mt 24,15-16). A base dessa possibilidade é a afirmação de Eusébio de Cesareia (265-339), o qual escreve que a Igreja de Jerusalém havia recebido um oráculo para que abandonasse a cidade antes que a guerra começasse e fosse morar na cidade de Pella (EH III:5). Talvez esse tenha sido o motivo da intensa ocupação de Pella por cristãos no período bizantino, de cuja época as construçôes de igrejas ainda hoje são visíveis. 
De Pella foram encontradas duas cartas em Tell el-Amarna: EA 255 e 256. O autor é Mut-Ba'lu, filho de Lab’ayu e governante de Pella. $\mathrm{Na}$ análise petrográfica, Goren, Finkelstein e Na'aman ${ }^{21}$ concluem que a cerâmica dos dois tabletes é proveniente de diferentes lugares da região. Ainda que, teoricamente, ambas as cartas possam ter sido enviadas de Pella, é mais provável que a EA 256 tenha sido enviada de Pella e a EA 255 de Betsã. Possivelmente Haya, o emissário do rei, ordenara a Mut-Ba 'lu a comparecer a Betsã, base militar egípcia, para receber instruçôes, oportunidade na qual a carta teria sido despachada ao Egito. Vejamos!

\section{EA 255: Mut-Ba'lu é acusado de reter as caravanas do Egito}

(8-11): O rei meu senhor enviou Ha'ya, para dizer: "Estou enviando caravanas para Hanigalbat, portanto, despache-as.

(12-21): Quem sou eu para não despachar as caravanas do rei meu senhor? Veja [La]b'ayu, meu pai, [sempre serv] viu o rei, seu senhor, [e ele] sempre despachou [todas as cara] vanas [que] o rei [queria] enviar para a terra de Hanigalbat e para a terra de Karaduniyash.

(22-25): Que o rei, meu senhor, envie caravanas. Eu mesmo vou conduzi-las sob forte guarda.

A EA 255 é também uma carta breve, mas bem preservada ${ }^{22}$ que, fora a apresentação e submissão (1-7), trata de um único problema: o envio de caravanas. Ela revela um problema comercial e político muito sério. A carta é resposta a uma ordem recebida do emissário do faraó, de nome Ha'ya, para que Mut-Ba 'lu despache as caravanas enviadas pelo faraó a Hanigalbat e Karaduniyash. Hanigalbat era a designação para Mitani e Karaduniyash para a Babilônia, dois grandes parceiros comerciais do Egito durante o período de Amarna. Ou seja, o precioso e imenso comércio entre o Egito e o norte e sul da Mesopotâmia tinha que passar por Pella.

De forma que, a cidade tinha um papel histórico no controle das caravanas (12-21), sendo uma espécie de portão por onde elas tinham que passar. E a cidade agora era governada por Mut-Ba'lu, filho do arqui-inimigo do faraó. E, pelo que a carta deixa transparecer, as caravanas eram retidas (saqueadas?) por Mut-Ba'lu, e por isso a repreensão do faraó. Entende-se que a função de Mut-Ba lu não era somente deixar o caminho livre para as caravanas, mas a de escoltá-las até o seu destino. E isso parece que não estava acontecendo.

${ }^{21}$ Goren, Finkelstein e Na'aman, Inscribed in Clay: Provenance Study of the Amarna Letters and other Ancient Near Eastern Texts, 262.

${ }^{22}$ Baranowski, “Amarna Letters No. 255 as a Diplomatic Correspondence: A New Interpretation”, 13-20. 
Mut-Ba'lu se faz de desentendido e afirma que não tem porque o faraó temer, pois Lab'ayu, seu pai, sempre serviu ao faraó e de que ele pessoalmente irá conduzir as caravanas. Ou seja, o que se supóe é de que Mut-Ba'lu se aliara a seu pai Lab’ayu, retinha as caravanas egípcias, possivelmente utilizando os bens em benefício da revolta. E, por isso, o ultimato do faraó ao seu vassalo ou ex-vassalo. Mut-Ba'lu sabe o que significa desafiar o faraó, por isso também o tom de total submissão da carta, muito similar à atitude de Tagi, sogro de Milkilu. Novamente a diplomacia cumpre seu papel. Fica claro, portanto, que o clima é de tensão entre o faraó e seu comandado rebelde.

A segunda carta de Mut-Ba'lu é para o comissário Yanhamu, como se verá a seguir.

\section{EA 256: Mut-Ba'lu e Ayyab}

(1-4): Diga ao Yanhamu, meu senhor, a mensagem de Mut-Ba'lu, seu servo. Aos pés do meu senhor eu caio.

(4-10): Como se pode dizer na tua presença "Mut-Ba'lu fugiu. Ele escondeu Ayyab"? Como pode o governante de Pihilu fugir do comissário do rei, seu senhor?

(10-19): Como vive o rei, meu senhor, como vive o rei, meu senhor, eu juro, Ayyab não está em Pihilu. Aliás, ele es[teve no cam]po por dois meses. Pergunte a Ben-Elima, pergunte a Tadua, pergunte a Yashuya.

(19-28): Depois que ele roubou Shulum-Marduk, eu fui pelo auxílio de Ashtartu, quando todas as cidades de Garu ficaram hostis: a cidade de Udumu, a cidade de Aduru, a cidade de Araru, a cidade de Mishta, a cidade de Magdal, a cidade de 'Eni-'anabi, a cidade de Zarqu, a cidade de 'Ayonu e a cidade de Yobilu foram tomadas.

(29-35): Além disso, vendo isso, depois que você enviou o tablete a mim, eu escrevi para ele. E, antes da vossa chegada da viagem, ele provavelmente já terá chegado a Pihilu, e eu certamente irei obedecer vossas ordens.

Mut-Ba'lu recebeu uma carta do comissário do faraó (29-35), na qual é acusado de dois crimes: de ter fugido ou se ocultado da sua presença, talvez durante uma visita, e de ter escondido a Ayyab. O comissário do faraó tinha grande poder e costumava ser o responsável por determinada região, sobre a qual, muitas vezes, o faraó nem tinha conhecimento. Ele também comandava o exército na região. O temor de Mut-Ba'lu expresso na carta é uma mostra do poder que um comissário tinha. Aqui se trata de Yanhamu, já muito conhecido em outras cartas (EA 83; 85; 98; 102; 105; 106; 109; $116 ; 117 ; 118 ; 127 ; 131 ; 132 ; 215$ etc.).

A acusação maior parece ser o fato de Mut-Ba'lu esconder Ayyab. Conforme a EA 364, Ayyab se encontra em conflito com o rei de Hazor, que lhe tomara o controle 
de algumas cidades. Segundo a análise petrográfica da EA 364²3, ela é procedente de Astarot (Ashtartu). Portanto, Astarot seria a capital de Ayyab. A localização da cidade ficava na Transjordânia, ao norte de Ramot-Gilead, e era, segundo $\mathrm{Na}^{\prime} \operatorname{aman}^{24}$, o reino mais importante da regiâo do Basá, ao nível de Damasco, com grande influência sobre as cidades-Estado ao seu entorno.

O fato de estar em guerra com o rei de Hazor, grande aliado do faraó, pode ser um indício de que Ayyab fosse um aliado de Mut-Ba'lu, o qual o escondera da perseguição do comissário Yanhamu. Mas, o problema não acaba aqui. Ayyab parece ter roubado/saqueado as caravanas da Babilônia (Shulum-Marduk), o que coloca esta carta no mesmo plano da anterior (EA 255), onde Mut-Ba'lu é acusado de reter as caravanas do faraó.

Enfim, o problema de fundo parece claro. Mut-Ba'lu, governante de Pella, e Ayyab, governante de Astarot, são aliados e ambos estão interceptando as caravanas comerciais vindos do Egito e da Babilônia. Portanto, o que Lab’ayu e Tagi estáo fazendo na regiáo oeste do Vale de Jezreel, Mut-Ba'lu e Ayyab estáo fazendo no leste. A revolta siquemita está se expandindo.

As demais cidades mencionadas na carta (19-28) se encontram na Transjordânia, pelo menos as que são identificáveis. O ambiente descrito é de total ebulição social.

\section{A revolta de lab'ayu e a revolta saul}

Os livros de 1 e 2Samuel ocultam antigas memórias do reinado de Saul, conhecido como primeiro rei (chefe) de Israel. Apesar da redação deuteronomista encobrir grande parte dos fatos históricos, é possível delinear o território que este reino chegou a controlar. O principal conjunto de textos onde se encontram preservadas estas memórias é $1 \mathrm{Sm}$ 9-(12)1425. Estes capítulos mencionam um conjunto de aldeias: Gibeá (gibe'ah), Gebá (geba) e Gibeon (gibề $n$ ). Todas estas aldeias têm em comum a raiz $g b^{\prime}$ (montanha) e delimitam o território onde nasceu e se formou o reino de Saul, no coração da montanha de Benjamin.

Mas, há ainda outros textos dos livros de Samuel que indicam em que direção se estendeu o reinado de Saul. Por exemplo: 1Sm 1-4, que traz antigas memórias de Ana e Elcaná, da montanha de Efraim, e do santuário de Silo; $1 \mathrm{Sm} \mathrm{31}$, que trata da morte de Saul no monte Gelboé pelos filisteus e da solidariedade dos habitantes de

${ }^{23}$ Goren, Finkelstein e Na'aman, Inscribed in Clay: Provenance Study of the Amarna Letters and other Ancient Near Eastern Texts, 218.

${ }^{24} \mathrm{Na}$ 'aman, "Biryawaza of Damascus and the date of Kamid El-Loz 'Apiru Leters", 181-182.

${ }^{25}$ Van Seters. Em busca da história. Historiografia no mundo antigo e as origens da história biblica, 264-276. 
Jabes de Gilead com Saul; 2Sm 2, que sucintamente faz uma interessante referência ao território controlado por Isbaal, filho de Saul. Ao analisar com detalhes todos estes textos é possível perceber, com relativa evidência, que o território que abrangia o iniciante reino de Saul é muito similar ao território ocupado pela revolta de Lab’ayu ${ }^{26}$.

\section{Conclusão}

As cartas enviadas por Lab'ayu ao Egito (EA 252; 153; 254) retratam um forte clima de tensão entre o faraó e seu vassalo ou ex-vassalo. Nas três cartas, Lab’ayu procura o tempo todo se defender de acusaçóes recebidas por parte do faraó: de ser rebelde, criminoso, de reter o tributo, de invadir outras cidades, de causar a perda das terras do faraó e de não entregar seu filho que está em conluio com os 'apirus. São acusaçôes sérias que retratam o início da rebelião em Canaã, que pode ser resumida nas seguintes frases: "Quem sou eu para que o rei perca a sua terra por causa de mim?" (254,6-10) e "Quando as formigas são feridas elas atacam de volta" (252,16-22).

As três cartas enviadas por Tagi (EA 264; 265; 266), governante de Ginti-Kirmil, não têm o mesmo tom de confronto das cartas de Lab'ayu. Além de serem bastante breves e de não fazerem menção a problemas internos, muito comuns em outras cartas, as cartas de Tagi se caracterizam pelo exagero da submissão e adulação. Exemplo é a EA 266, de cujas 33 linhas, 25 são de reverência ao faraó. Mais vulnerável do que seu genro, Tagi tem que se agarrar ao artifício da diplomacia para evitar uma ação mais dura do faraó. Contudo, a confissão encontrada no cilindro de Betsã mostra quem é seu verdadeiro senhor: Lab’ayu, o rei de Siquém e líder da revolta.

No outro extremo do Vale de Jezreel, Mut-Ba'lu, filho de Lab'ayu e governante de Pella, é acusado de reter/saquear as caravanas do rei do Egito (EA 255) e de ocultar a Ayyab, governante de Atarot, que, por sua vez, saqueava as caravanas da Babilônia (EA 256). Pella e Atarot eram duas grandes cidades-Estado localizadas junto ao caminho dos reis, na Transjordânia. Seus governantes são aliados e desenvolvem no leste as mesmas atividades rebeldes que Lab'ayu e Tagi desenvolvem no oeste da região.

Ou seja, a revolta siquemita, que começou nas montanhas centrais de Canaá, adquiriu importantes aliados e se estendeu para o oeste, até Ginti-Kirmil, e para o leste, até Pella e Atarot. Este, em boa parte, é o mesmo território que mais tarde abrigará o reino nascente de Israel Norte, com Saul.

\footnotetext{
${ }^{26}$ Para uma análise detalhada do território ocupado por Saul, ver Kaefer, "À procura de Saul! Uma análise de Primeiro Samuel 9-(12)14", 402-426; Finkelstein, “The Last Lab’ayu: King Saul and the Expansion of the First North Israelite Territorial Entity”, 171-193.
} 


\section{Referências}

Baranowski, Krzysztof. "Amarna Letters No. 255 as a Diplomatic Correspondence: A New Interpretation”. Aula Orientalis 32/1 (2014): 13-20.

Bogaert, Pierre-Maurice y otros. Diccionario enciclopédico de la Biblia. Barcelona: Herder, 1993.

Campbell, Edward. "Shechem in the Amarna Archive". En Shechem: The Biography of a Biblical City, por G. Ernest Wright, 191-207. New York (NY): McGrawHill, 1965.

Cochavi-Raney, Zipora (ed.). The El-Amarna Correspondence. A New Edition of the Cuneiform Letters from de Site of El-Amarna Based on Collations of all Extant Tablets. Vol. 2. Leiden-Boston: Brill, 2015.

Finkelstein, Israel. "The Last Lab'ayu: King Saul and the Expansion of the First North Israelite Territorial Entity". En Essays of Ancient Israel in Its Near Eastern Context. A Tribute to Nadav Na'aman, por Y. Amit; E. Ben Zevi; I. Finkelstein; e O. Lipchits, 171-193. Wininona Lake (IN): Eisenbraus, 2006.

Finkelstein, Israel e Nadav Na'aman. "Shechem of the Amarna Period and the Rise of the Northern Kingdom of Israel”. Israel Exploration Journal 55 (2005): 172-193.

Goren, Yuval; Israel Finkelstein; Nadav Na'aman. Inscribed in Clay: Provenance Study of the Amarna Letters and other Ancient Near Eastern Texts. Tel Aviv: Tel Aviv University, 2004.

Hendel, Ron. "The Exodus as Cultural Memory: Egyptian Bondage and the Song of the Sea”. En Israel's Exodus in Transdisciplinary Perspective. Quantitative Methods in the Humanities and Social Sciences, por T. E. Levy y otros, 65-77. Cham (Switzerland): Springer International Publishing, 2015.

Horowitz, Wayne. "An Inscribed Clay Cylinder from Amarna age Beth Shean". Israel Exploration Journal 46 (1996): 208-217.

Kaefer, José Ademar. "À procura de Saul! Uma análise de Primeiro Samuel 9-(12)14". Horizonte 42 (2016): 402-426.

. Arqueologia das terras da Bíblia. São Paulo: Paulus, 2012.

. "As cartas de Tell El-Amarna e o contexto egípcio nos reinados de Amenhotep III e Amenhotep IV (Akenaton)”. Estudos de religião 32/1 (2018): 121-140.

Moran, William. The Amarna Letters. Baltimore-London: The Johns Hopkins University Press, 1992. 
Mynarová, Jana. "A Comment on the Opening Passages of the Amarna Letters. Its Structure and Its Address". Archiv orientálni-Quaterly Journal of African and Asian Studies 73 (2005): 397-406.

. Language of Amarna: Language of Diplomacy. Perspectives on the Amarna Letters. Praga: University of Prague Press, 2007.

Na'aman, Nadav. "Biryawaza of Damascus and the date of Kamid El-Loz 'Apiru Leters”. Ugarit-Forschungen 20 (1988):179-193.

. "The Contribution of the Amarna Letters to the Debate on Jerusalem's Political Position in the Tenth Century B. C. E". Bulletin of the American Schools of Oriental Research 304 (1996): 17-27.

Rainey, Anson. The El-Amarna Correspondence. A New Edition of the Cuneiform Letters from de Site of El-Amarna Based on Collations of all Extant Tablets. LeidenBoston: Brill, 2015.

Van Seters, John. Em busca da história. Historiografia no mundo antigo e as origens da história bíblica. São Paulo: Editora da Universidade de São Paulo, 2008. 